\title{
Algorithm for Determining the Knock Resistance of LNG
}

\author{
Martijn Van Essen ${ }^{1, *}$, Sander Gersen ${ }^{1}$, Gerco Van Dijk ${ }^{1}$, Maurice Van Erp ${ }^{2}$, En Howard Levinsky ${ }^{3}$ \\ ${ }^{1}$ DNV-GL Oil \& Gas, Groningen, The Netherlands \\ ${ }^{2}$ Shell Projects \& Technology, Rijswijk, The Netherlands \\ ${ }^{3}$ Energy and Sustainability Research Institute, University of Groningen, Groningen, The Netherlands
}

\section{Email address:}

M.vanEssen@dnvgl.com (M. V. Essen)

${ }^{*}$ Corresponding author

\section{To cite this article:}

Martijn Van Essen, Sander Gersen, Gerco Van Dijk, Maurice Van Erp, En Howard Levinsky. Algorithm for Determining the Knock Resistance of LNG. International Journal of Energy and Power Engineering. Vol. 8, No. 2, 2019, pp. 18-27. doi: 10.11648/j.ijepe.20190802.12

Received: May 28, 2019; Accepted: July 10, 2019; Published: July 24, 2019

\begin{abstract}
This paper reports the development of a next-generation algorithm to calculate the knock resistance for LNG compositions. This so-called PKI Methane Number is developed and tested for a lean-burn, medium-BMEP gas engine. The algorithm itself is a polynomial equation based on thousands of simulations performed using an experimentally verified engine knock model. Comparison of the PKI MN calculated using the gas-input-only algorithm and measurements on the test engine show very good agreement. A comparison with two existing methods for calculating the methane number (AVL and MWM Method as defined in EN 16726) with experimental engine data show reasonable agreement with predictions using AVL method but substantial differences with predictions from MWM method are observed. Additionally, the current methods such as AVL and MWM need a dedicated solver to calculate the methane number. In contrast, the algorithm described here is a polynomial equation that is very easy to implement in gas composition sensors for fast real-time methane number calculations. This opens possibilities for smart-phone methane number calculation during bunkering and fuel-adaptive control systems that could optimize engine performance for a broad range of fuel compositions. Furthermore, given the experimentally verified reliability and ease of implementation of the PKI MN algorithm, we assert that it is an excellent, open-source candidate for international standards for specifying the knock resistance of LNG.
\end{abstract}

Keywords: LNG, Methane Number, Engine Knock, Algorithm

\section{Introduction}

LNG is becoming increasingly relevant and popular as a fuel in marine and road applications, owing to its increasing worldwide availability in combination with its favorable emissions characteristics and lower noise production compared with traditional engine fuels.

LNG is produced at different locations around the world. Due to differences in natural gas reservoirs, production technologies and target markets for the LNG, the composition of the LNG (the 'quality') may vary substantially with the geographical origin [1]. Furthermore, the "boil-off" of the volatile components during LNG transport, transfer and storage leads to a change in composition, also known as "LNG aging". Such LNG quality aspects must be considered in assessing the fitness for purpose of the LNG for the end user. Gas composition variations in LNG influence the so-called knock resistance of the fuel [2]. This characteristic describes the tendency of a given fuel composition to cause 'knocking' in the engine during combustion. Poor knock resistance leads to engine knock, which can severely compromise engine performance, varying from increased pollutant emissions and reduced fuel efficiency to engine failure [3].

The knock resistance of LNG is characterized by a methane number, which is similar to the octane number used to qualify gasoline. In the 1970s, AVL was one of the first to develop a tool to calculate the methane number for gaseous fuels [4]. The AVL methane number uses a methane-hydrogen scale; pure methane is a knock resistant fuel and is assigned a value of 100 , while hydrogen is knock sensitive and is given the value of 0 . Based on experimental results, AVL developed a fitting procedure to predict the methane number of a gas mixture using methane number diagrams based on ternary mixtures [4]. The AVL method 
uses a propriety program to calculate the methane number. Several empirical methods [4-18] have been developed since then and some of them use the data from the original experimental work performed by AVL on a stochiometric engine in the 1970s [3]. For example, the MWM method (published in the standard EN 16726, 2015) is based on the same data and methodology as AVL and extended the range of hydrocarbons up to $3 \%$ of each component of C5, C6 and C7 [9, 11]. In contrast to AVL, the MWM method ignores the effect of nitrogen, stating that nitrogen has no impact on the knock resistance of lean-burn engines [11]. Both MWM and AVL use complex relations to find the methane number iteratively for a given gas composition. This is a hurdle for easy integration of these methods into gas analysis equipment such as real time gas sensors used for determining the methane number of a fuel at bunker stations or used in fuel-adaptive engine control systems that need real-time determination of the knock resistance of the fuel [21, 22]. Furthermore, the selection of a transparent and accurate method for ranking the knock resistance of LNG fuels to serve as an international standard [18-20] is an important subject of current attention.

To ensure that modern engines to be used in LNG-fuelled ships and trucks are matched with the expected variations in fuel composition, in this paper we demonstrate a next-generation, open source, easy-to-implement algorithm to calculate the methane number of LNG compositions based on the Propane Knock Index Methane Number (PKI MN) [23-24].

Having an accurate algorithm to calculate the knock resistance safeguards the end user by ensuring that engine performance is not unnecessarily compromised (for example, by derating) or is unnecessarily at risk. It also ensures that gases are not excluded from the market, or "overtreated" to remove knock-enhancing components without cause. The algorithm developed in this study is a polynomial equation that is straightforward to use and, in contrast to existing methods, straightforward to integrate in gas composition sensors for real-time methane number calculations.

\section{Approach}

The gas-input-only algorithm presented below is based on computations using a detailed numerical model that simulates engine processes governing knock when varying the fuel composition. As discussed in [23], the numerical model was developed to quantify the knock resistance of LNG for a high-speed, lean-burn, medium-BMEP, spark-ignited CHP engine, whose operating conditions are presented in Table 1. Rather than rely on the empirical methods traditionally employed to characterize the knock resistance of gases, such as the original methane number, the numerical model characterizes the knock resistance based on the fundamental combustion properties of the fuel mixtures. Here we recall that engine knock is caused by autoignition of the unburned fuel mixture, the so-called end gas, ahead of the propagating flame in the engine cylinder. The core of the model to predict engine knock is the computation of the autoignition process during the compression and burn periods of the engine cycle. The input data needed for the numerical model are: the engine geometry, in-cylinder conditions ( $\mathrm{P}, \mathrm{T})$ at valve closure, operating conditions such as spark timing, air factor, humidity and the fuel composition. Based on the input data, the model calculates the knock resistance of a given gaseous fuel for which a propane-based scale is used that we have developed previously [23]. In this scale, which we refer to as Propane Knock Index (PKI), the knock resistance for a given gaseous fuel mixture is expressed by the model as an equivalent fraction of propane in methane under the identical engine conditions. As shown in [23] the simulated knock propensity calculated by the model, expressed as PKI, is in excellent agreement with the experimentally measured knock propensity (KLST) in the test engine for a wide range of fuel compositions, including admixtures of $\mathrm{H}_{2}, \mathrm{CO}$ and $\mathrm{CO}_{2}$ in natural gas. In Figure 1 we replot the compositions of hydrocarbons and nitrogen relevant for characterizing the range of LNG compositions (the compositions are listed in Table 5, below). As in Ref. [23], the variation in predicted PKI and experimental KLST as a function of fuel composition is within the uncertainty of the measurements $\left( \pm 0.75^{\circ} \mathrm{C} \mathrm{A}\right)$.

Table 1. Specifications test engine [23].

\begin{tabular}{ll}
\hline Engine make \& type & MAN E2876LE302 \\
\hline & -6 cylinder in-line \\
Engine configuration & - turbocharged \\
& - intercooled \\
Combustion system \& combustion & - mono-gas \\
stoichiometry & - open chamber \\
Rated power \& speed & - lean-burn $(\lambda=1.55)$ \\
(corresponding BMEP) & $208 \mathrm{~kW}$ at $1500 \mathrm{rpm}(13.0 \mathrm{bar})$ \\
Bore x Stroke & $128 \times 166 \mathrm{~mm}$ \\
Compression ratio & $11.0: 1$ \\
\hline
\end{tabular}

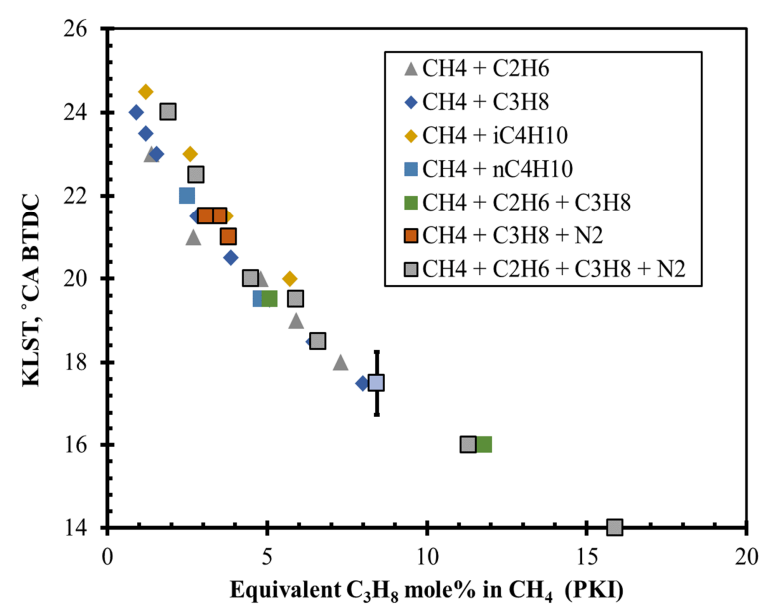

Figure 1. Calculated knock resistance (PKI) versus measured knock resistance (KLST).

Based on the correlation between measurements and calculations observed in Figure 1 we conclude that the knock model accurately captures the physics and chemistry that 
determine engine knock for the range of compositions relevant for $\mathrm{LNG}$.

\subsection{Conversion PKI to Normalized 0-100 Scale}

As mentioned above, traditional methane number methods use a methane-hydrogen scale, with 100 having the knock equivalent of pure methane, and 0 being nominally assigned to hydrogen. The propane/methane-based scale (PKI) derived previously [23] has pure methane is $\mathrm{PKI}=0$, increasing linearly with the equivalent propane content. To convert this scale to a $0-100$ scale for comparison with the methane/hydrogen-based scale used by AVL and others, the PKI data was fit with a sixth-order polynomial shown in Equation (2), below, to generate a normalized Knock Index, referred to as the PKI Methane Number [23].

$$
\begin{gathered}
\text { PKI MN = } 100.01-9.757977 \times \mathrm{PKI}+1.484961 \times \mathrm{PKI}^{2}-0.139533 \times \mathrm{PKI}^{3}+7.031306 \times 10^{-3} \times \mathrm{PKI}^{4}- \\
1.770029 \times 10^{-4} \times \mathrm{PKI}^{5}+1.751212 \times 10^{-6} \times \mathrm{PKI}^{6}
\end{gathered}
$$

The polynomial is optimized for multicomponent mixtures spanning the range of LNG compositions that are expected to be encountered in practice: PKI is expressed in one decimal place and ranges from 0-20, which approximately corresponds to the PKI MN range of 100-53. Figure 2 shows the correlation between the PKI methane number and the measured KLST [23]. As is the case in Figure 1, the spread in the data in Figure 2 is within the experimental uncertainty.

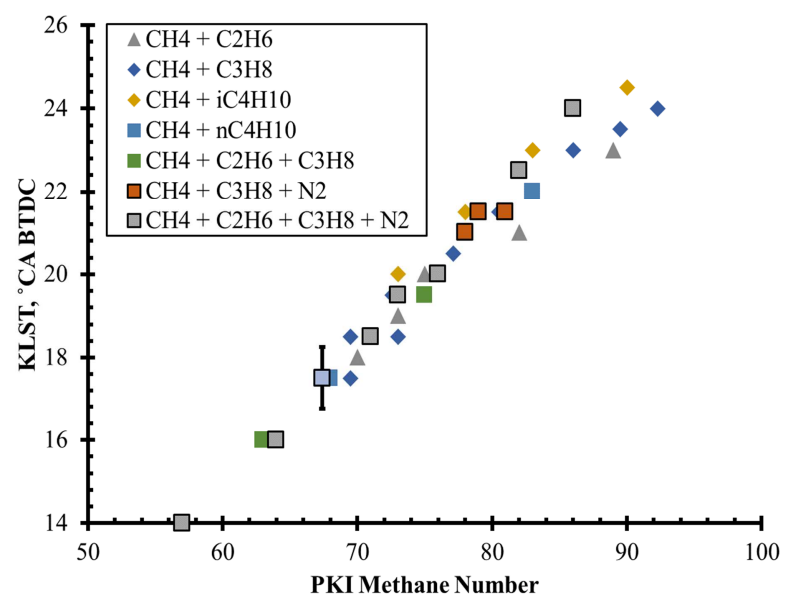

Figure 2. Calculated knock resistance (PKI MN) versus measured knock resistance (KLST).

\subsection{Algorithm Development}

To generate data for the gas-only-input that covers the spectrum of LNGs consisting of $\mathrm{CH}_{4}, \mathrm{C}_{2} \mathrm{H}_{6}, \mathrm{C}_{3} \mathrm{H}_{8}, \mathrm{i}-\mathrm{C}_{4} \mathrm{H}_{10}$, $\mathrm{n}-\mathrm{C}_{4} \mathrm{H}_{10}, \quad \mathrm{n}-\mathrm{C}_{5} \mathrm{H}_{12}$, i- $\mathrm{C}_{5} \mathrm{H}_{12}$, neo- $\mathrm{C}_{5} \mathrm{H}_{12}$ and nitrogen, we performed simulations of gas mixtures using the engine knock model described above. The simulations in the knock model are performed at fixed engine- and experimental conditions: excess air ratio, $\lambda=1.55$, a relative humidity of $0 \%$ and an intake temperature of $64^{\circ} \mathrm{C}$ at the engine conditions presented in Table 1.

The LNG composition ranges used in the simulations are listed in Table 2 and the range of PKI for multicomponent mixtures is $0-20$ (corresponding to $\mathrm{PKI} M N$ ranging from 100 to 53, respectively). Consonant with the range of PKI $\mathrm{MN}$, the range of compositions chosen for the algorithm is also intended to cover the range of $\mathrm{LNG}$ compositions expected to be encountered in practice.
Table 2. Range of fuel compositions used for the development of the algorithm.

\begin{tabular}{lll}
\hline Species & Min. mole \% & Max. mole \% \\
\hline $\mathrm{CH}_{4}$ & 70 & 100 \\
$\mathrm{C}_{2} \mathrm{H}_{6}$ & 0 & 20 \\
$\mathrm{C}_{3} \mathrm{H}_{8}$ & 0 & 10 \\
$\mathrm{n}-\mathrm{C}_{4} \mathrm{H}_{10}$ & 0 & 5 \\
$\mathrm{i}-\mathrm{C}_{4} \mathrm{H}_{10}$ & 0 & 5 \\
$\mathrm{n}-\mathrm{C}_{5} \mathrm{H}_{12}$ & 0 & 0.15 \\
$\mathrm{i}-\mathrm{C}_{5} \mathrm{H}_{12}$ & 0 & 0.15 \\
$\mathrm{Neo}_{2}-\mathrm{C}_{5} \mathrm{H}_{12}$ & 0 & 0.15 \\
$\mathrm{~N}_{2}$ & 0 & 20 \\
\hline
\end{tabular}

Based on the LNG gas composition range shown in the Table 2, a test matrix consisting of several thousand compositions was generated for binary $\left(\mathrm{CH}_{4} / \mathrm{C}_{\mathrm{x}} \mathrm{H}_{\mathrm{y}}\right.$ and $\left.\mathrm{CH}_{4} / \mathrm{N}_{2}\right)$ and ternary $\left(\mathrm{CH}_{4} / \mathrm{C}_{\mathrm{x}} \mathrm{H}_{\mathrm{y}} / \mathrm{C}_{\mathrm{x}} \mathrm{H}_{\mathrm{y}}\right.$ and $\left.\mathrm{CH}_{4} / \mathrm{C}_{\mathrm{x}} \mathrm{H}_{\mathrm{y}} / \mathrm{N}_{2}\right)$ fuel mixtures. For this test matrix, the engine knock model calculates PKI for the corresponding gas composition. Subsequently, a least squares regression analyses was performed on the computed PKI values for these mixtures to develop the algorithm. Towards this end, a polynomial was used to calculate the PKI from the mole fractions of the individual components, shown in equation (2):

$$
P K I=\sum \alpha_{i^{n}} X_{i}^{n}+\sum \beta_{i^{n}{ }^{m}} m X_{i}^{n} X_{j}^{m}
$$

Here, $\mathrm{X}$ is the mole fraction, $\mathrm{i}, \mathrm{j}=\mathrm{CH}_{4}, \mathrm{C}_{2} \mathrm{H}_{6}, \mathrm{C}_{3} \mathrm{H}_{8}, \mathrm{i}-\mathrm{C}_{4} \mathrm{H}_{10}$, $n-\mathrm{C}_{4} \mathrm{H}_{10}, n-\mathrm{C}_{5} \mathrm{H}_{12}, \mathrm{i}-\mathrm{C}_{5} \mathrm{H}_{12}$, neo- $\mathrm{C}_{5} \mathrm{H}_{12}$ and $\mathrm{N}_{2}$ with $\mathrm{i} \neq \mathrm{j}, \mathrm{n}=$ $1-4$ and $m=1,2$. The coefficients $\alpha$ and $\beta$ of the polynomial were determined from the least squares analyses that best fit the PKI values from the test matrix.

As an example of the simulation results using the knock model, the binary mixtures for the C1-C5 mixtures are presented in Figure 3. From this Figure it can be clearly seen that the knock behavior, expressed in the propane knock index (PKI) differs substantially among the components studied. As expected, the knock resistance for the straight chain hydrocarbons increases with the size of the hydrocarbon (n-pentane $>$ n-butane $>$ propane $>$ ethane). However, both iso-butane and iso-pentane show substantially different behavior than n-butane and n-pentane, respectively. As can be seen from Figure 3, the knock resistance of n-butane is significantly lower than i-butane. Furthermore, the knock resistance for the pentanes increases with the increase in chain branching (n-pentane $>$ i-pentane $>$ neo-pentane). The results also show the importance of 
considering the isomers of butane and pentane individually in the method. Traditional methods such as AVL and MWM do not differentiate between the isomers of butane and pentane $[4,9,11]$.

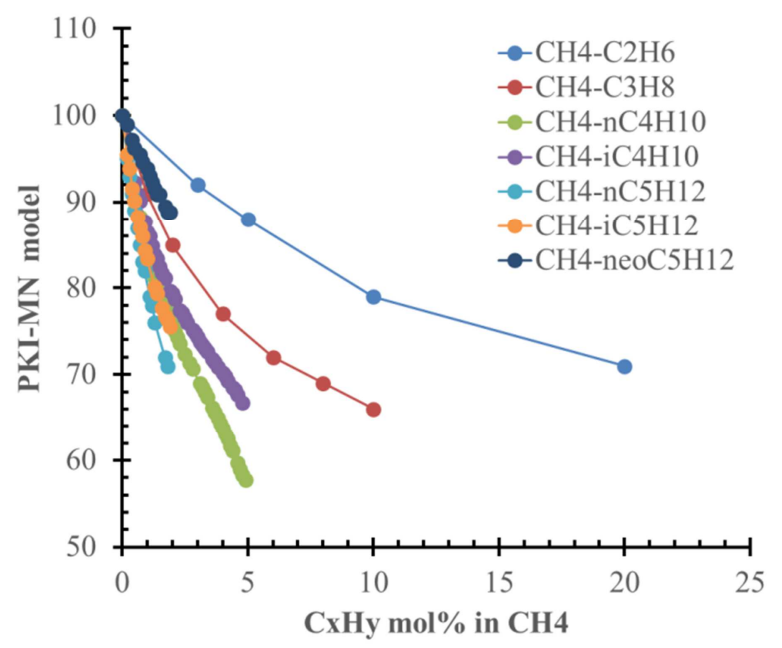

Figure 3. PKI MN computed with the numerical model as a function of mole percentage ethane, propane, $n$-butane, i-butane, n-pentane, $i$-pentane or neo-pentane in methane.

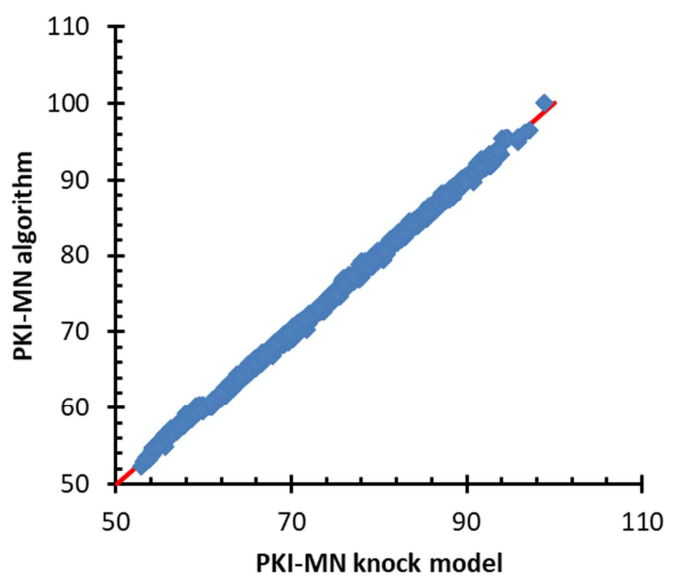

Figure 4. PKI MN values calculated by using the integrated knock model versus the PKI MN values calculated by using equation (2).

In Figure 4, the results of the PKI simulations using the knock model for all gas mixtures used in the matrix are plotted against the PKI values calculated by the algorithm using the coefficients given in Table 6. As can be seen from the Figure, the predictions of the gas-input-only algorithm (equation 2) are in excellent agreement with the PKI values derived from the knock model. The average deviation between the model results and the algorithm predictions is $0.15 \mathrm{PKI} \mathrm{MN}$, while the maximum difference is roughly 0.7 PKI MN.

To test the algorithm further, we calculated the PKI MN for the range of gas compositions measured in the engine [7] (Table 5). Figure 5 shows the KLST measurements plotted versus the PKI MN calculated using the algorithm. Although the agreement is generally still within the uncertainty in the KLST measurements, the maximum spread of $\pm 3.5 \mathrm{PKI} \mathrm{MN}$ is significantly larger than that observed in Figure 2. The origin of this larger spread lies in the fact that the algorithm (Figure 5) is based on fixed engine conditions while model results shown in Fig.2 accounts for the measured variations in the experimental conditions, such as air humidity and intake temperature, which can substantially impact the knock resistance, as discussed previously [24].

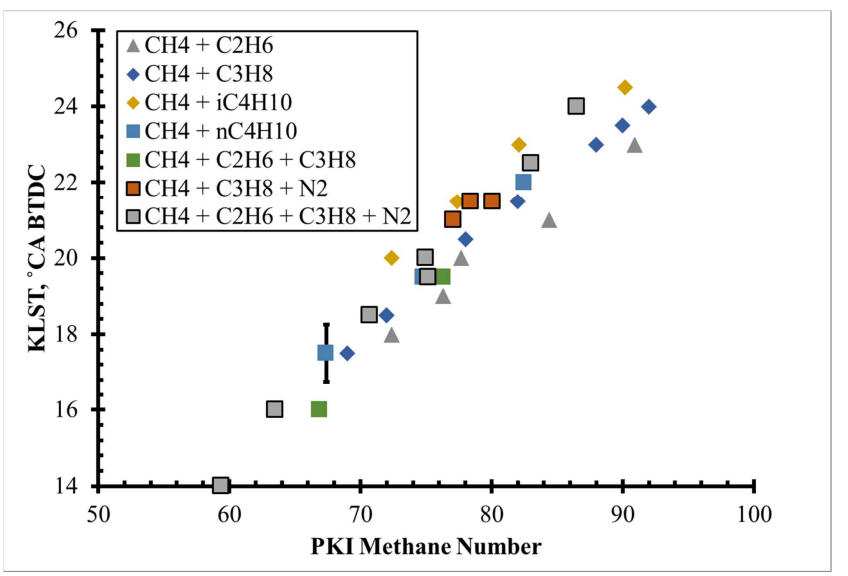

Figure 5. Experimentally determined knock resistance (KLST) versus PKI MN calculated by the algorithm, equation (2).

\subsection{Comparison with Other Methane Number Methods}

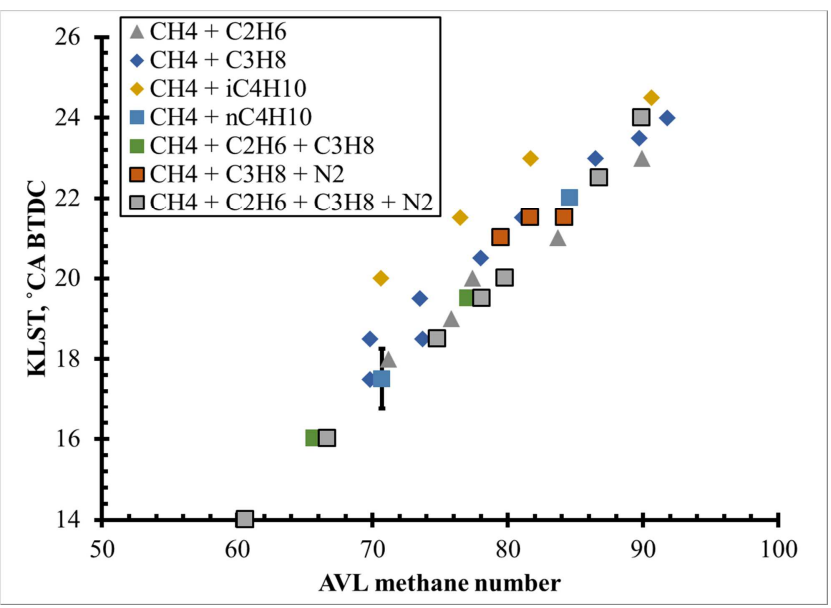

Figure 6. Calculated AVL MN vs KLST.

To compare the performance of the traditional methane numbers with the PKI MN using the same benchmark, the methane numbers using AVL and MWM for the mixtures in Table 5 (used in Figures. 2 and 5), are also plotted versus the measured knock resistance (KLST) in Figures 6 and 7 , respectively. With the exception of the measurements on mixtures containing iso-butane, the measured and calculated knock resistance using the AVL method shown in Figure 6 are within the experimental uncertainty; for all data, the maximum variation in the AVL Methane Number at constant spark timing being roughly \pm 4.5 . Since the AVL method treats both n-butane and i-butane as n-butane, the knock resistance of the i-butane mixtures is systematically underpredicted, as observed in the Figure.

Comparison between the measured KLST and the 
calculated methane number using the MWM method, presented in Figure 7, shows the largest spread; the maximum deviation at constant KLST is \pm 6 points. Here, the spread seems to be caused by the lack of differentiation among the butane isomers, with an apparent overprediction of the knock resistance for n-butane and apparent underprediction for i-butane. Interestingly, for the gas compositions studied, large differences are observed between the AVL- and the MWM methane numbers, while both methods are based on the same binary and ternary data sets data sets [4], with the exception of nitrogen. In contrast to AVL, the MWM method ignores the effect of nitrogen, asserting that nitrogen has no impact on the knock resistance of lean-burn engines [11]. However, as can be seen in Table 5, MWM differs substantially from AVL (up to $7 \mathrm{MN}$ ) even for hydrocarbon mixtures without nitrogen. Whether this discrepancy is accidental or intentional, the absence of experimental data verifying the adequacy of the MWM algorithm (as compared to AVL) clouds the range of applicability of the method. We also observe that the results for the AVL method are closer to those of the PKI MN than MWM, while AVL was developed for stoichiometric engines and MWM was optimized for lean-burn systems.

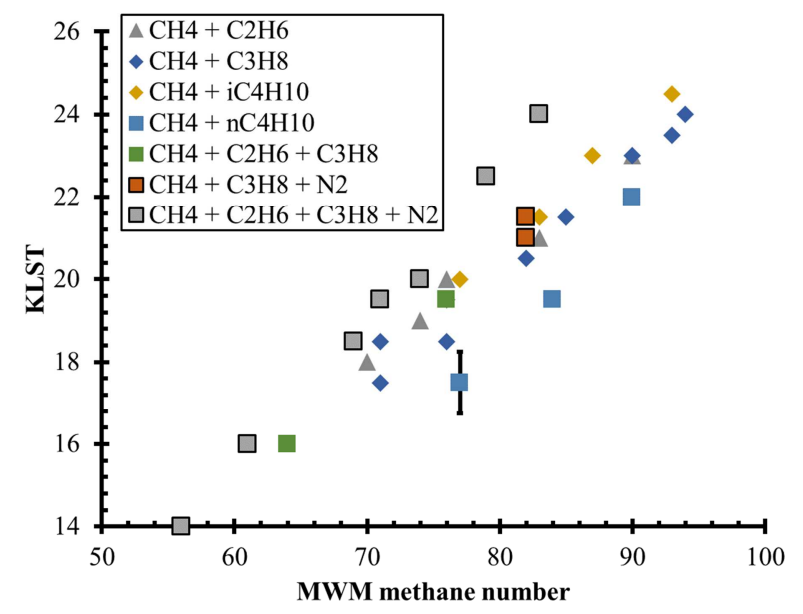

Figure 7. Calculated MWM methane number vs KLST.

\subsection{Comparison with Other Data}

Despite the fact that the PKI MN algorithm described here was developed for the engine characterized in Table 1 , it is interesting to compare the predictions of this algorithm for other engine platforms. Recently, experiments were performed to examine the effects of natural gas composition on the phenomenon of 'rapid combustion' in a dual-fuel engine [25]. In that paper, a number of binary and ternary fuel compositions were examined, where the excess air ratio, $\lambda$, was varied until rapid combustion occurred; the mixtures were chosen to have a constant MWM methane number. The authors concluded that the transition to rapid combustion was poorly predicted by the MWM method. In Table 3, we show the results from that paper for three mixtures nominally characterized as $\mathrm{MWM}=80$. The experimental $\lambda$ at transition varied from $>3.4$ to 1.95 at constant MWM methane number; while the physical relation between the PKI MN and the measured excess air ratio at the transition to rapid combustion is unknown at present, the PKI MN predicts the qualitative trends well.

Table 3. Transition to rapid combustion for different fuel mixtures having $M W M=80$.

\begin{tabular}{llll}
\hline Mixture & $\begin{array}{l}\text { Transition to rapid } \\
\text { combustion, } \boldsymbol{\lambda}\end{array}$ & MWM MN & AVL MN \\
\hline $\mathrm{CH}_{4} / \mathrm{C}_{4} \mathrm{H}_{10}$ & $>3.4$ & 79 & 73 \\
$\mathrm{CH}_{4} / \mathrm{C}_{3} \mathrm{H}_{8} / \mathrm{C}_{4} \mathrm{H}_{10}$ & 2.7 & 81 & 76 \\
$\mathrm{CH}_{4} / \mathrm{C}_{2} \mathrm{H}_{6} / \mathrm{C}_{3} \mathrm{H}_{8}$ & 1.95 & 83 & 79 \\
\hline
\end{tabular}

Another set of KLST experiments has recently been performed on a stoichiometric truck engine [26]. The dedicated algorithm developed for this engine showed a variation in methane number vs. KLST of $< \pm 1$, while MWM and AVL (developed for a stoichiometric engine) gave spreads of $\pm 6-7$ and \pm 3.5 , respectively. Although the complete analysis of the phasing and knock characteristics of the stoichiometric engine with varying LNG composition is outside the scope of this paper ${ }^{1}$, we report that the algorithm presented here, developed for the lean-burn engine, shows a variation in the PKI MN algorithm at constant KLST of better than \pm 2 . Thus, compared to experimental assessment of engine knock (or rapid combustion) as a function of gas composition, the algorithm presented outperforms the existing methods, even for non-lean-burn engine platforms.

\subsection{Variations in Methods for LNG Compositions}

To compare the differences that can be expected from the different methods to determine the methane number for LNG compositions experienced in practice, we compute the methane numbers for the well-known GIIGNL [1] list of LNG compositions using the different methods. The results are presented in Table 4. Given the results presented in Figure 5 and 6 it is not surprising that the PKI MN and AVL MN give similar methane numbers, with a maximum deviation of $2 \mathrm{MN}$. However, in contrast to the results presented in Figure 5 and 7 the differences between the PKI MN and the MWM methods (and, of course, the AVL MN as well) shown in Table 4 are relatively small. The minor differences observed are partially explained by the limited gas composition variation, and the lack of differentiation between butane isomers in the AVL and MWM methods.

We also observe that the MWM method can yield large uncertainty for binary and ternary mixtures, when compared to PKI MN (and AVL), particularly for the mixtures containing butanes and propane, either as fuel compositions in experiments or in the field, if they occur. This can partially be ascribed to the physical representation of the effects of these fuels, as seen in combination with the KLST measurements discussed above, but also to algorithmic uncertainties. For example, while the LNG composition designated as "Equatorial Guinea" in Table 4 gives MWM=85, addition of $0.001 \%$ butane suddenly drops the value to $M W M=82$, which

\footnotetext{
1 Gersen, et al., "Phasing and engine knock in a stoichiometric modern truck engine", manuscript in preparation.
} 
is not physically realistic. We conclude that caution is advised when considering such mixtures.

\section{Summary and Conclusions}

This paper reports the development of a next-generation algorithm to calculate the methane number based on the Propane Knock Index Methane Number (PKI MN) for LNG compositions. The PKI MN algorithm is developed and tested for a lean-burn, medium-BMEP gas engine. The algorithm itself is a polynomial equation based on thousands of simulations performed using an experimentally verified engine knock model. The agreement between the new gas-input-only algorithm and the numerically calculated PKI $\mathrm{MN}$ from the knock model is smaller than 0.7 methane number points, with an average deviation is only $0.15 \mathrm{MN}$ points. Comparison of the PKI MN calculated using the gas-input-only algorithm and measurements on the test engine show very good agreement, with a maximum spread between the calculated and measured knock resistance of $\pm 3.5 \mathrm{MN}$.

Comparison of existing methane number methods with the experimental knock resistance show reasonable agreement with the predictions using the AVL method; a maximum variation in the AVL Methane Number at constant spark timing of roughly \pm 4.5 is observed for the gases tested. The largest deviation with the measurements is observed for i-butane since AVL does not distinguish between i-butane and n-butane. The largest spread between the measured KLST and the calculated methane number was observed using the MWM method with a maximum deviation at constant KLST of about
6. Although developed for the lean-burn test engine studied, the PKI MN algorithm also predicts the experimental performance of a dual-fuel engine and a stoichiometric truck engine better than the other methods. Despite the substantial differences observed when comparing the computed methane numbers and KLST measurements, calculations of the methane number for 'commercial' LNG compositions show only minor differences between the three methods, with a maximum deviation of two methane number points. These minor differences are partially explained by the limited gas composition variation, low nitrogen concentration in the fuel and lack of differentiation among the butane isomers in the AVL and MWM methods. It is important to note that the MWM method can yield substantial uncertainty for binary and ternary mixtures, either as fuel compositions in experiments or in the field, if they occur.

Additionally, the current methods such as AVL and MWM need a dedicated solver to calculate the methane number. In contrast, the algorithm described here, and given in Table 6 , is a polynomial equation that is very easy to implement in gas composition sensors for fast real-time methane number calculations. This opens possibilities for smart-phone methane number calculation during bunkering and fuel-adaptive control systems that could optimize engine performance for a broad range of fuel compositions. Furthermore, given the experimentally verified reliability and ease of implementation of the PKI MN algorithm, we assert that it is an excellent, open-source candidate for international standards for specifying the knock resistance of LNG.

Table 4. Calculated methane numbers for GIIGNL gases [8] by using different methods ${ }^{2}$ [3-5,7].

\begin{tabular}{|c|c|c|c|c|c|c|c|c|}
\hline & $\mathrm{CH}_{4}, \%$ & $\mathrm{C}_{2} \mathrm{H}_{6}, \%$ & $\mathrm{C}_{3} \mathrm{H}_{8}, \%$ & $\mathrm{C}_{4} \mathrm{H}_{10}, \%$ & $\mathrm{~N}_{2}, \%$ & PKI MN & AVL MN & MWM MN \\
\hline Australia NWS & 87.4 & 8.3 & 3.3 & 1.0 & 0.0 & 69 & 69 & 68 \\
\hline Australia Darwin & 87.6 & 10.0 & 2.0 & 0.3 & 0.1 & 72 & 73 & 71 \\
\hline Algeria Skikda & 91.3 & 7.4 & 0.6 & 0.1 & 0.6 & 79 & 80 & 78 \\
\hline Algeria Bethioua & 89.6 & 8.2 & 1.3 & 0.3 & 0.6 & 75 & 76 & 75 \\
\hline Algeria Arzew & 88.9 & 8.4 & 1.6 & 0.4 & 0.7 & 74 & 75 & 73 \\
\hline Brunei & 90.2 & 5.3 & 3.0 & 1.5 & 0.0 & 68 & 69 & 69 \\
\hline Egypt Idku & 95.4 & 3.6 & 0.7 & 0.3 & 0.0 & 82 & 84 & 84 \\
\hline Equatorial Guinea & 93.4 & 6.5 & 0.1 & 0.0 & 0.0 & 84 & 84 & 85 \\
\hline Indonesia Arun & 91.8 & 5.7 & 1.6 & 0.8 & 0.1 & 74 & 75 & 75 \\
\hline Indonesia Badak & 90.1 & 5.5 & 3.0 & 1.4 & 0.0 & 69 & 69 & 70 \\
\hline Indonesia Tangguh & 96.9 & 2.4 & 0.4 & 0.2 & 0.1 & 88 & 88 & 88 \\
\hline Libya & 82.5 & 12.6 & 3.6 & 0.7 & 0.6 & 67 & 67 & 65 \\
\hline Malaysia & 91.8 & 4.6 & 2.6 & 0.9 & 0.1 & 72 & 73 & 73 \\
\hline Nigeria & 91.7 & 5.5 & 2.2 & 0.6 & 0.0 & 74 & 75 & 75 \\
\hline Oman & 90.7 & 5.8 & 2.1 & 1.2 & 0.2 & 71 & 72 & 72 \\
\hline Peru & 89.0 & 10.3 & 0.1 & 0.0 & 0.6 & 78 & 78 & 79 \\
\hline Qatar & 90.9 & 6.4 & 1.7 & 0.7 & 0.3 & 74 & 75 & 74 \\
\hline Russia Sakhalin & 92.4 & 4.5 & 2.0 & 1.0 & 0.1 & 73 & 74 & 75 \\
\hline Trinidad & 96.7 & 2.8 & 0.4 & 0.1 & 0.0 & 87 & 88 & 88 \\
\hline USA Alaska & 99.7 & 0.1 & 0.0 & 0.0 & 0.2 & 100 & 100 & 100 \\
\hline Yemen & 93.2 & 5.9 & 0.8 & 0.1 & 0.0 & 80 & 82 & 80 \\
\hline
\end{tabular}

2 Butane has been taken as a mixture of $50 \%$ i-butane and $50 \%$ n-butane 


\section{Acknowledgements}

The authors gratefully acknowledge Shell Global Solutions for financial support of the development of the algorithm for LNG.

\section{Appendix}

Table 5. Measured gas compositions with calculated methane numbers.

\begin{tabular}{|c|c|c|c|c|c|c|c|c|c|}
\hline $\mathrm{CH} 4$ & 96.6227 & 93.3292 & 88.6489 & 87.2163 & 82.4093 & 81.1135 & 91.1541 & 98.8028 & 97.865 \\
\hline $\mathrm{C} 2 \mathrm{H} 6$ & 3.3771 & 6.6706 & 11.3508 & 12.7837 & 17.5907 & 13.6989 & 6.5886 & 0 & 0 \\
\hline $\mathrm{C} 3 \mathrm{H} 8$ & 0 & 0 & 0 & 0 & 0 & 5.1254 & 2.2465 & 0 & 0 \\
\hline $\mathrm{n}-\mathrm{C} 4 \mathrm{H} 10$ & 0 & 0 & 0 & 0 & 0 & 0.0205 & 0.0107 & 1.197 & 2.135 \\
\hline i-C4H10 & 0 & 0 & 0 & 0 & 0 & 0.0416 & 0 & 0 & 0 \\
\hline n-C5H12 & 0 & 0 & 0 & 0 & 0 & 0 & 0 & 0 & 0 \\
\hline i-C5H12 & 0 & 0 & 0 & 0 & 0 & 0 & 0 & 0 & 0 \\
\hline neo-C5H12 & 0 & 0 & 0 & 0 & 0 & 0 & 0 & 0 & 0 \\
\hline C6+ & 0.0002 & 0.0002 & 0.0003 & 0 & 0.0001 & 0.0001 & 0 & 0.0002 & 0 \\
\hline N2 & 0 & 0 & 0 & 0 & 0 & 0 & 0 & 0 & 0 \\
\hline $\mathrm{KLST},{ }^{\circ} \mathrm{CA} \mathrm{BTDC}$ & 23 & 21 & 20 & 19 & 18 & 16 & 19.5 & 22 & 19.5 \\
\hline PKI-MN & 91 & 84 & 78 & 76 & 72 & 67 & 76 & 83 & 75 \\
\hline MWM-MN & 90 & 83 & 76 & 74 & 70 & 64 & 76 & 90 & 84 \\
\hline AVL-MN & 90 & 84 & 77 & 76 & 71 & 66 & 77 & 85 & 77 \\
\hline $\mathrm{CH} 4$ & 96.5913 & 99.3173 & 98.45 & 97.6981 & 96.5738 & 90.01 & 92.3274 & 92.33 & 94.2355 \\
\hline $\mathrm{C} 2 \mathrm{H} 6$ & 0 & 0 & 0 & 0 & 0 & 0 & 0.1611 & 0.102 & 0.1116 \\
\hline C3H8 & 0 & 0 & 0 & 0 & 0 & 9.99 & 7.4061 & 7.525 & 5.5821 \\
\hline $\mathrm{n}-\mathrm{C} 4 \mathrm{H} 10$ & 3.4087 & 0 & 0 & 0 & 0 & 0 & 0.0287 & 0.043 & 0.0222 \\
\hline i-C4H10 & 0 & 0.6824 & 1.55 & 2.3019 & 3.4262 & 0 & 0.0763 & 0 & 0.0482 \\
\hline n-C5H12 & 0 & 0 & 0 & 0 & 0 & 0 & 0 & 0 & 0 \\
\hline i-C5H12 & 0 & 0 & 0 & 0 & 0 & 0 & 0 & 0 & 0 \\
\hline neo-C5H12 & 0 & 0 & 0 & 0 & 0 & 0 & 0 & 0 & 0 \\
\hline $\mathrm{C}^{+}+$ & 0 & 0.0003 & 0 & 0 & 0 & 0 & 0.0005 & 0 & 0.0004 \\
\hline N2 & 0 & 0 & 0 & 0 & 0 & 0 & 0 & 0 & 0 \\
\hline $\mathrm{KLST},{ }^{\circ} \mathrm{CA} \mathrm{BTDC}$ & 17.5 & 24.5 & 23 & 21.5 & 20 & 15.5 & 17.5 & 18.5 & 18.5 \\
\hline PKI-MN & 67 & 90 & 82 & 77 & 72 & 66 & 70 & 70 & 73 \\
\hline MWM-MN & 77 & 93 & 87 & 83 & 77 & 67 & 71 & 71 & 76 \\
\hline AVL-MN & 71 & 91 & 82 & 77 & 71 & 67 & 70 & 70 & 74 \\
\hline $\mathrm{CH} 4$ & 94.155 & 96.029 & 96.9175 & 98.213 & 98.7983 & 99.095 & 90.0858 & 85.0032 & 77.4783 \\
\hline $\mathrm{C} 2 \mathrm{H} 6$ & 0.098 & 0 & 0.0599 & 0 & 0 & 0 & 0 & 0 & 0 \\
\hline C3H8 & 5.665 & 3.94 & 2.999 & 1.781 & 1.1936 & 0.902 & 3.6852 & 3.3898 & 3.1454 \\
\hline $\mathrm{n}-\mathrm{C} 4 \mathrm{H} 10$ & 0.082 & 0.031 & 0.0133 & 0.006 & 0.0075 & 0.003 & 0.0157 & 0.0145 & 0.0133 \\
\hline i-C4H10 & 0 & 0 & 0.0099 & 0 & 0 & 0 & 0.029 & 0.0236 & 0.0192 \\
\hline n-C5H12 & 0 & 0 & 0 & 0 & 0 & 0 & 0 & 0 & 0 \\
\hline i-C5H12 & 0 & 0 & 0 & 0 & 0 & 0 & 0 & 0 & 0 \\
\hline neo-C5H12 & 0 & 0 & 0 & 0 & 0 & 0 & 0.0001 & 0.0001 & 0.0002 \\
\hline C6+ & 0 & 0 & 0.0004 & 0 & 0.0005 & 0 & 0 & 0 & 0 \\
\hline N2 & 0 & 0 & 0 & 0 & 0 & 0 & 6.1842 & 11.5689 & 19.3438 \\
\hline $\mathrm{KLST},{ }^{\circ} \mathrm{CA} \mathrm{BTDC}$ & 19.5 & 20.5 & 21.5 & 23 & 23.5 & 24 & 21 & 21.5 & 21.5 \\
\hline PKI-MN & 73 & 77 & 81 & 86 & 90 & 92 & 77 & 78 & 80 \\
\hline MWM-MN & 76 & 82 & 85 & 90 & 93 & 94 & 82 & 82 & 82 \\
\hline AVL-MN & 74 & 78 & 81 & 87 & 90 & 92 & 80 & 82 & 84 \\
\hline
\end{tabular}

Table 6. Coefficients PKI algorithm (equation 2).

\begin{tabular}{ll}
\hline Coefficient & Value \\
\hline$\alpha_{\mathrm{CH}_{4}}$ & 569.285536016002 \\
$\alpha_{\left(\mathrm{CH}_{4}\right)^{2}}$ & -650.8543394907 \\
$\alpha_{\left(\mathrm{CH}_{4}\right)^{3}}$ & 64.3595752573862 \\
$\alpha_{\left(\mathrm{CH}_{4}\right)^{4}}$ & 17.2149592220536 \\
$\alpha_{\mathrm{C}_{2} \mathrm{H}_{6}}$ & -645.099966662855 \\
$\alpha_{\left(\mathrm{C}_{2} \mathrm{H}_{6}\right)^{2}}$ & 694.229376857102 \\
$\alpha_{\left({ }_{2} \mathrm{H}_{6}\right)^{3}}$ & -675.381075231165 \\
$\alpha_{\left(\mathrm{C}_{2} \mathrm{H}_{6}\right)^{4}}$ & 1474.79079137333 \\
\hline
\end{tabular}




\begin{tabular}{|c|c|}
\hline Coefficient & Value \\
\hline$\alpha_{C_{3} H_{8}}$ & 499.39849265152 \\
\hline$\alpha_{\left(c_{3} H_{8}\right)^{2}}$ & -576.665945472394 \\
\hline$\alpha_{\left(C_{3} H_{8}\right)^{3}}$ & 252.19367406028 \\
\hline$\alpha_{\left(C_{3} H_{8}\right)^{4}}$ & 593.958975466507 \\
\hline$\alpha_{n-C_{4} H_{10}}$ & 934.46627322324 \\
\hline$\alpha_{\left(n-C_{4} H_{10}\right)^{2}}$ & -86.8723570770238 \\
\hline$\alpha_{\left(n-C_{4} H_{10}\right)^{3}}$ & -20418.9067673979 \\
\hline$\alpha_{\left(n-C_{4} H_{10}\right)^{4}}$ & 633286.561358521 \\
\hline$\alpha_{i-C_{4} H_{10}}$ & 735.223884113728 \\
\hline$\alpha_{\left(i-C_{4} H_{10}\right)^{2}}$ & -3182.61439337967 \\
\hline$\alpha_{\left(i-C_{4} H_{10}\right)^{3}}$ & 20945.1867250219 \\
\hline$\alpha_{\left(i-C_{4} H_{10}\right)^{4}}$ & 159067.868032595 \\
\hline$\alpha_{n-C_{5} H_{12}}$ & 2571.93079360535 \\
\hline$\alpha_{\left(n-C_{5} H_{12}\right)^{2}}$ & 10516.4941092275 \\
\hline$\alpha_{\left(n-C_{5} H_{12}\right)^{3}}$ & -770539.377197693 \\
\hline$\alpha_{\left(n-C_{5} H_{12}\right)^{4}}$ & 28633475.5865654 \\
\hline$\alpha_{i-C_{5} H_{12}}$ & -3582.96784435379 \\
\hline$\alpha_{\left(i-C_{5} H_{12}\right)^{2}}$ & 0.0 \\
\hline$\alpha_{\left(i-C_{5} H_{12}\right)^{3}}$ & 403155.950864334 \\
\hline$\alpha_{\left(i-C_{5} H_{12}\right)^{4}}$ & -11917333.8379329 \\
\hline$\alpha_{n e o-C_{5} H_{12}}$ & 1123.39636709865 \\
\hline$\alpha_{\left({\left.\text {neo- } C_{5} H_{12}\right)}^{2}\right.}$ & 1679.7280752481 \\
\hline$\alpha_{\left({\left.\text {neo- } C_{5} H_{12}\right)}^{3}\right.}$ & -172182.649067176 \\
\hline$\alpha_{\left(\text {neo-C } C_{5} H_{12}\right)^{4}}$ & 3467918.60746699 \\
\hline$\alpha_{N_{2}}$ & -469.428097827742 \\
\hline$\alpha_{\left(N_{2}\right)^{2}}$ & 352.688107288763 \\
\hline$\alpha_{\left(N_{2}\right)^{3}}$ & -220.491687402358 \\
\hline$\alpha_{\left(N_{2}\right)^{4}}^{4}$ & 1419.68005396242 \\
\hline$\beta_{\mathrm{CH}_{4} * \mathrm{C}_{2} \mathrm{H}_{6}}$ & 201.788909592169 \\
\hline$\beta_{\mathrm{CH}_{4} * \mathrm{C}_{3} \mathrm{H}_{8}}$ & -865.856657223225 \\
\hline$\beta_{\mathrm{CH}_{4} * n-C_{4} H_{10}}$ & -1210.2275419324 \\
\hline$\beta_{\left(C H_{4} * n-C_{4} H_{10}\right)^{2}}$ & 1331.55552369645 \\
\hline$\beta_{\mathrm{CH}_{4} * i-C_{4} H_{10}}$ & -1023.2781474703 \\
\hline$\beta_{\left(\mathrm{CH}_{4} * i-\mathrm{C}_{4} \mathrm{H}_{10}\right)^{2}}$ & 1550.09518461258 \\
\hline$\beta_{C_{4} * n-C_{5} H_{12}}$ & -2811.67740432523 \\
\hline$\beta_{\mathrm{CH}_{4} * i-C_{5} \mathrm{H}_{12}}$ & 3363.98150506356 \\
\hline$\beta_{\mathrm{CH}_{4} * \text { neo- } \mathrm{C}_{5} \mathrm{H}_{12}}$ & -1534.52567488723 \\
\hline$\beta_{\mathrm{CH}_{4} * N_{2}}$ & -1.05397332930609 \\
\hline$\beta_{C_{2} H_{6} * C_{3} H_{8}}$ & 0.0 \\
\hline$\beta_{C_{2} H_{6} * n-C_{4} H_{10}}$ & -437.695363730406 \\
\hline$\beta_{C_{2} H_{6} * i-C_{4} H_{10}}$ & -109.983789902769 \\
\hline$\beta_{C_{2} H_{6} * n-C_{5} H_{12}}$ & -1870.34746500563 \\
\hline$\beta_{C_{2} H_{6} * i-C_{5} H_{12}}$ & 3909.50906076245 \\
\hline$\beta_{C_{2} H_{6} * \text { neo }-C_{5} H_{12}}$ & -886.578525827322 \\
\hline$\beta_{C_{2} H_{6} * N_{2}}$ & 968.887620927515 \\
\hline$\beta_{C_{2} H_{6}^{2} * N_{2}}$ & 267.47276619196 \\
\hline$\beta_{C_{2} H_{6} * N_{2}^{2}}$ & 337.464863958288 \\
\hline$\beta_{C_{3} H_{8} * n-C_{4} H_{10}}$ & -118.490180710956 \\
\hline$\beta_{C_{3} H_{8} * i-C_{4} H_{10}}$ & 0.0 \\
\hline$\beta_{C_{3} H_{8} * n-C_{5} H_{12}}$ & -1734.80568239427 \\
\hline
\end{tabular}




\begin{tabular}{ll}
\hline Coefficient & Value \\
\hline$\beta_{C_{3} H_{8} * n-C_{5} H_{12}^{2}}$ & 127551.642193201 \\
$\beta_{C_{3} H_{8}^{2} * n-C_{5} H_{12}}$ & 11318.4183950722 \\
$\beta_{C_{3} H_{8} * i-C_{5} H_{12}}$ & 3318.96820819338 \\
$\beta_{C_{3} H_{8} * n e o-C_{5} H_{12}}$ & 0.0 \\
$\beta_{C_{3} H_{8} * N_{2}}$ & 13.3453378124692 \\
$\beta_{n-C_{4} H_{10} * i-C_{4} H_{10}}$ & 3500.70282852274 \\
$\beta_{n-C_{4} H_{10} * n-C_{5} H_{12}}$ & -4737.328494494999 \\
$\beta_{n-C_{4} H_{10} * n-C_{5} H_{12}^{2}}$ & 525591.310711326 \\
$\beta_{n-C_{4} H_{10}^{2} * n-C_{5} H_{12}}$ & 297556.039242685 \\
$\beta_{n-C_{4} H_{10} * i-C_{5} H_{12}}$ & 6095.05998875087 \\
$\beta_{n-C_{4} H_{10} * n e o-C_{5} H_{12}}$ & -953.002183779388 \\
$\beta_{n-C_{4} H_{10} * N_{2}}$ & 0.0 \\
$\beta_{i-C_{4} H_{10} * n-C_{5} H_{12}}$ & 5056.60309163761 \\
$\beta_{i-C_{4} H_{10} * i-C_{5} H_{12}}$ & 6619.27877637044 \\
$\beta_{n-C_{4} H_{10} * n e o-C_{5} H_{12}}$ & -1363.96101644841 \\
$\beta_{i-C_{4} H_{10} * N_{2}}$ & 14.8038957999724 \\
$\beta_{n-C_{5} H_{12} * i-C_{5} H_{12}}$ & 12268.283772748 \\
$\beta_{n-C_{5} H_{12} * n e o-C_{5} H_{12}}$ & 0.0 \\
$\beta_{n-C_{5} H_{12} * N_{2}}$ & -1573.68893770625 \\
$\beta_{i-C_{5} H_{12} * n e o-C_{5} H_{12}}$ & 3773.44926785397 \\
$\beta_{i-C_{5} H_{12} * N_{2}}$ & 4490.67830032675 \\
$\beta_{n e o-C_{5} H_{12} * N_{2}}$ & -642.170828416611 \\
\hline
\end{tabular}

\section{References}

[1] The LNG industry GIIGNL Annual Report 2017, http://www.giignl.org/

[11] "Gas Methane Number Calculation MWM method", April 2013 (documentation Euromot MWM tool).

[12] Methane number calculation of natural gas mixtures, http://mz.dgc.eu./

[13] http://www.cumminswestport.com/fuel-quality-calculator

[2] M. van Essen, S. Gersen, G. van Dijk, H. Levinsky, T. Mundt, G. Dimopoulos and N. Kakalis, "The effect of boil off on the knock resistance of LNG gases", CIMAC Congress, Helsinki, Finland, June 6-10, 2016, paper 123.

[3] J. B. Heywood, International Combustion Engine fundamentals, McGraw-Hill, 1989.

[4] M. Leiker, W. Cartelliere, H. Christoph, U. Pfeifer, and M. Rankl, (1972) Evaluation of Anti-Knock Property of Gaseous Fuels by Means of the Methane Number and Its Practical Application, ASME paper 72-DGP-4.

[5] California Alternative Fuels for Motor Vehicle Regulations Appendix D: Methane Number and fuel composition, https://www.arb.ca.gov/regact/cng-lpg/appd.pdf

[6] Gary Choquette, "Analysis and estimation of stoichiometric air-fuel ratio and methane number for natural gas", 23rd Gas Machinery Conference, Nashville, USA, October 5-8, 2014.

[7] G. W. Sorge, R. J. Kakoczki, and J. E. Peffer, "Method for determining knock resistance rating for non-commercial grade natural gas", US Patent 6,061,637, May 9, 2000.

[8] R. T. Smith, G. W. Sorge, and J. R. Zurlo, "Systems and Methods for Engine Control Incorporating Fuel Properties", European Patent EP 2963270 A1, 25th May 2015.

[9] prEN16726: 2014 - Annex A.

[10] C. Rahmouni, G. Brecq, M. Tazerout, O. Le Corre, (2004) Knock rating of gaseous fuels in single cylinder spark ignition engine, Fuel 83 (3) 327-336.

[14] https://www.wartsila.com/products/marine-oil-gas/gas-solutio ns/methane-number-calculator

[15] https://www.dnvgl.com/oilgas/natural-gas/fitness-for-purposeof-lng-pki-methane-number-calculator.html

[16] https://www.dnvgl.com/oilgas/natural-gas/fitness-for-purposefor-pipeline-gas.html

[17] GasCalc

Software, http://www.eon.com/en/business-areas/technical-sercices/gasc alc-software.html

[18] EUROMOT position paper, "Methane number as a parameter for gas quality specifications", 2012.

[19] International group of liquefied natural gas importers, "Position paper on the impact of including methane number in natural gas regulation", 2015.

[20] See, for example, ISO/TC 28/SC 4/WG 17 "LNG as a marine fuel".

[21] Patrik Soltic, Hannes Biffiger, Philippe Pretre and Andreas Kempe (2016) Micro-thermal CMOS-based gas quality sensing for control of spark ignition engines, Measurement 91, 661-679.

[22] K. Saikaly, O. Le Corre, C. Rahmouni and L. Truffet (2010) Preventive Knock Protection Technique for Stationary SI Engines Fuelled by Natural Gas, Fuel Processing Technology 9 641-652.

[23] S. Gersen, M. van Essen, H. Levinsky, and G. Dijk (2016) Characterizing Gaseous Fuels for Their Knock Resistance based on the Chemical and Physical Properties of the Fuel, SAE Int. J. Fuels Lubr. 9 (1), doi: 10.4271/2015-01-9077. 
[24] M. van Essen, S. Gersen, G. Dijk, T. Mundt, et al. (2016) The Effect of Humidity on the Knock Behavior in a Medium BMEP Lean-Burn High-Speed Gas Engine, SAE Int. J. Fuels Lubr. 9 (3), doi: 10.4271/2016-01-9075.

[25] D. van Alstine, D. Montgomery, T. Callahan, and R. Florea, "Ability of the Methane Number Index of a Fuel to Predict Rapid Combustion In Heavy Duty Dual Fuel Engines for North American Locomotives", Proceedings of the ASME 2015 Internal Combustion Engine Division Fall Technical
Conference, November 8-11, 2015, Houston, TX, USA, paper ICEF2015-1119.

[26] TKI LNG report, a correct 'octane number' for LNG, report No.: $\quad$ OGNL.113944, 30-11-2017. https://www.researchgate.net/publication/321528353_A_corre ct_'octane_number'_for_LNG 